Journal of the Minnesota Academy of Science

Volume 10 | Number 1

Article 8

4-1942

\title{
A Comparison Of The Outcomes Of Instruction Of The Conventional High School Physics Course And The Generalized High School Senior Science Course
}

Robert H. Heidel

Follow this and additional works at: https://digitalcommons.morris.umn.edu/jmas

Part of the Science and Mathematics Education Commons

\section{Recommended Citation}

Heidel, R. H. (1942). A Comparison Of The Outcomes Of Instruction Of The Conventional High School Physics Course And The Generalized High School Senior Science Course. Journal of the Minnesota Academy of Science, Vol. 10 No.1, 34-36.

Retrieved from https://digitalcommons.morris.umn.edu/jmas/vol10/iss1/8

This Article is brought to you for free and open access by the Journals at University of Minnesota Morris Digital Well. It has been accepted for inclusion in Journal of the Minnesota Academy of Science by an authorized editor of University of Minnesota Morris Digital Well. For more information, please contact skulann@morris.umn.edu. 


\title{
Science Education
}

\section{RESCUING PHYSICS FROM THE TEXTBOOKS- EXPERIMENTAL DEMONSTRATIONS}

\author{
R. M. Sutton \\ Haverford College, Haverford, Pennsylvania
}

THE BORDER-LINE FIELD IN SCIENCE EDUCATION

\author{
Abe Pepinsky . \\ University of Minnesota
}

A COMPARISON OF THE OUTCOMES OF INSTRUCTION OF THE CONVENTIONAL HIGH SCHOOL PHYSICS COURSE AND THE GENERALIZED HIGH SCHOOL SENIOR SCIENCE COURSE

\section{Robert H. HeIDeL \\ Chaska High School}

The problem of this study was to measure and compare some of the purported outcomes of instruction of a generalized high school senior science course stressing practical applications and consumer education, and a conventional high school physics course employing the lecture-demonstration method and stressing classical applications and problems. Data for this investigation were obtained by the administration initially and terminally, or terminally, of two forms of one examination and one form each of nine other examinations to the students of the sophomore, junior, and senior classes of the Chaska High School, Chaska, Minnesota enrolled in senior science and physics during the academic year 1940-41.

Representativeness of groups was indicated by the fact that no statistically significant difference existed between the means of the intelligence quotients of the senior science group and the physics group of this study and the respective means of the intelligence quotients of previous senior science and physics classes of the school. To obtain a measure of the initial status of some of the functions to be experimented upon in this study a physics test designed to measure certain outcomes in the field of physics common to both groups, a standardized physics test, and a scientific attitudes test were administered, in addition to two forms of the Terman Group Test of Mental Ability. 
From the data collected in this study it was found that the means of -the test scores of the physics group exceeded the means of the test scores of the senior science group in every examination with the exception of the means of the scores on the Consumer Information test. Where examinations were administered initially and terminally to the two groups, it was found that in the case of the senior group there was a significant gain on the Designed Physics test while there were no significant changes on the Attitudes test and the Cooperative Physics examination. The physics group likewise showed no significant changes on the Attitudes test on final over initial test scores. In the case of the Designed Physics test and the Physics Form 0 examination the physics group showed highly significant gains after the period of instruction covering two semesters. The difference in gains on these two tests was also significantly greater for the physics group than for the senior science group. When the usual test of significance was applied to the differences in changes on the Attitudes test between the senior science group and the physics group, no significant difference was found. However, in applying a more rigorous method of measuring changes, it was indicated that the two groups differed significantly on the changes in the Attitudes test scores.

Data on the several criteria tests administered initially and measuring various learning capacities showed that large inequalities existed between the groups. The problem was to compare differences in achievement when differences in learning capacity as measured by the initial criteria tests were taken into account.

Using the methods of the analysis of variance and covariance, it was found that differences in means on the attitudes test adjusted for inequalities of the two groups with respect to mental test scores were significantly in favor of the senior science group, while in the case of the Evaluation of Advertising test no significant difference existed between the two groups. No significant difference was found between the adjusted means of the senior science and the physics groups on the General Science test scores when the factors of learning ability as measured by the Intelligence test were taken into consideration. Likewise, no significant differences were found between the means of the senior science group and the physics group on the Consumer Information and the Consumer Applications test scores adjusted for inequalities with respect to mental test scores.

In the case of the means on the final Designed Physics test of the senior science group and the physics group adjusted for mental ability and initial status on the Designed Physics test, no significant difference existed between these means.

Highly significant differences in adjusted means in favor of the physics group were found on the test scores of the Physics Form 0 examination, the Physics Applications test, and the 1941 Minnesota State Board Physics examination. 
The results of the investigation are summarized as follows:

(1) The generalized high school senior science course and the conventional high school physics course are both effective in bringing about significant gains in knowledge of scientific facts and information of a general nature. Greatest gains took place in the conventional high school physics course probably because of the greater ability of the students enrolled in this type of course.

(2) The Generalized high school senior science course did not prove effective in bringing about significant gains in knowledge of specific physics materials while the conventional high school physics course proved effective in bringing about highly significant gains in knowledge and understandings of physics materials.

(3) Although significant differences existed between the students of the generalized high school senior science course and the students of the conventional high school physics course on scientific attitudes as measured by the Noll's Attitudes test, neither the generalized high school senior science course nor the conventional high school physics course proved effective in bringing about significant changes in scientific attitudes.

(4) The generalized high school senior science course proved no less efficient than the conventional high school physics course in the teaching of general scientific facts or principles and applications of those principles to pupils when inequalities of mental ability and previous achievement were taken into consideration.

(5) The conventional high school physics course proved definitely superior to the generalized high school science course in developing in pupils understanding of specific physics materials as measured by several physics tests even after inequalities of mental ability and previous achievement were taken into account.

(6) The generalized high school senior science course proved no more effective than the conventional high school physics course in attaining by students the specific consumer outcomes or objectives as measured by several tests after the factors of inequality of mental ability were taken into consideration.

\title{
THE FUNCTION OF THE COLLEGE MUSEUM IN THE TEACHING OF BIOLOGY AND THE CONSER- VATION OF OUR WILD LIFE
}

\author{
M. M. KeITH \\ State Teachers College, Mankato
}

\section{Abstract}

At the spring meeting of the Minmesota Academy of Science held at the College of St. Catherine in St. Paul last spring, the Science Education Section voted to sponsor a plan to centralize and promote the use of the natural resources of the State and other aids 